\title{
Investigation of Participation Motivations in Exercises of Students Participating in Archery in Extra Curricular Activities
}

\author{
Nevin Gündüz ${ }^{1, *}$, Muzaffer Toprak Keskin ${ }^{2}$, Fuat Erduğan ${ }^{3}$ \\ ${ }^{1}$ Faculty of Sport Sciences, Ankara University, Turkey \\ ${ }^{2}$ Ministry of National Education, Hazım Kulak Anatolian High School, Turkey \\ ${ }^{3}$ Kirkpınar School of Physical Education and Sports, Trakya University, Turkey
}

Copyright $\bigcirc 2017$ by authors, all rights reserved. Authors agree that this article remains permanently open access under the terms of the Creative Commons Attribution License 4.0 International License

\begin{abstract}
The aim of this research is to investigate Investigation of Participation Motivations in Exercises of Students Participating in Archery in Extra Curricular Activities. While the study's universe consists of all $11^{\text {th }}$ graders studying at High school, the sample includes 32 of the $11^{\text {th }}$ grade students who participated in arrow shooting activities in extracurricular activities. These students have not participated in arrow shooting activities before, and do not know how to shoot arrows. In the qualitative part of the research, a total of 18 students including 9 female and 9 male volunteers participated. In this study, the arrow shooting activity covers a total of 12 weeks, once a week, two lesson hours. Exercise Participation Motivation Inventory was used as the quantitative data collection tool in the research and it was applied to the students at the end of 12 weeks. Also, skills assessment test prepared by teacher and trainer were applied before and after 12 weeks to evaluate the skill of archery and semi-structured interview questions (8 questions) were applied for qualitative data. According to the quantitative results of the research, "Skill Development" is the most important motivational factor that motivates students to participate in exercise before 12 weeks of activity and afterwards Students' average scores related to the subscales in the Participation Motivations of Exercise before 12 weeks of activity were found to be "Health", "Competition", "Appearance", "Social and Entertainment" and "Skill Development". After 12 weeks of activity, it is found that students' average scores show increase in "Health", "Competition", "Appearance", "Social and Entertainment", and "Skill Development" sub-dimensions. A t-test was performed on the related samples to determine whether this increase was significant or not and it was found to be statistically significant. A t-test was conducted between students' pre-test and post-test averages of the students' shooting arrow skill test before and after 12 weeks of the activity and a statistically significant difference was determined $(\mathrm{P}=0.00)$. According to the results of the

qualitative analysis of the study, these students were very pleased with arrow shooting, their attention to these spores and concentration increased, and most importantly, they stated that their opinion regarding physical education course changed positively.

Keywords Extracurricular Activities, Shooting Arrow, Participation Motivation in Exercise

\section{Introduction}

Archery has become a sport branch that has come to be a day-to-day recreation to as wells being on instrument of war and hunting in the historical process (Atabeyoğlu, [1]), it has become a modern sport in the course of time and become an interesting and exciting sport (Randal, [2]). Interest in archery sport is increasing day by day. According to the results of the 2012 London Olympics, it was the most watched branch in the first week and again in the same week it was signified that it had received 30, 000 more tweets than other branches (Lee, [3]).In this sport which can be played with a bow, a target, and enough arrows various small aids, it is aimed to shoot yellow and collect high scores. (Kolayiş et. al. [4]).

For a good performance in shooting arrow sport; the reaction time, the ability to concentrate on the target, the ability to have adequate conditioning and technical properties, and the psychological status are important. Apart from these, that the material used is adequate and appropriate, weather conditions are well, good use of the time given in order to get fair points in the competition, the environment is quiet, a balanced and repeatable drop and a stable posture are very important. Even though it is a physical activity, archery sport normally requires a great deal of mental focus to control the body (Lee, [3] and Kürşat, [5]).
\end{abstract}


Extracurricular activities are activities planned and programmed under the guidance of the school management in order to develop their personalities in relation to the interest and need of the students (Ekici et.al. [6]). In addition, students' interest in academic works, physical strength and social mobility and respectability both inside/outside the school are increasing (Ardahan et. al. [7])Extracurricular activities are an important part of education; that's why, many countries made participation in them obligatory to increase quality in education. For instance, in Japan moral education is provided with sports and cultural events more. Extracurricular activity is essential in Malaysia at all levels of education. Again, as a means of moral development in China, physical education and fine arts activity courses are given importance (Köse, [8]). Similarly, in Norway, international and national documents have been identified for schools to encourage young people to physical activity. Schools offer opportunities to students for lunch and between meals to be physically active (Torsheim et.al. [9]).

In Kanters, [10], it is stated that after school activities are a promising practice to increase spore participation. Some of the questions asked in the studies on individuals participating in recreational activities in national and international literature are why individuals participate in these activities and why they do not participate and what encourages individuals to participate (Kim, et.al. [11]). It can be said that motivational factors are important at participation in sports. Motivation is defined as motivating, activating and encouraging person to work (Soyer, et.al.[12]). In another definition, motivation is internal and external stimuli that direct a person to a certain action (Altıntaş, [13]). External stimuli; are benefits and prizes that will be earned out of the individual if the assignment is fulfilled. Internal stimuli; are relative interest in the individual and the pleasure received (Wann, [14]). Interest in activity plays an important role in increasing motivation to participate in exercise. The motivation for participation in the exercise program may vary depending on the purpose of the activity being undertaken (skill-based, similar leisure or social activities... etc.) (Gillard, et. al. [15]).

Schools are centers that initially support children and young people to attend physical activities, because the school is located in every society, it is expected that physical education lessons are compulsory in the schools and they have possibilities to support physical activity. Moreover, inter-class competitions applied in schools offer opportunities for students to join in a variety of activities (Kanters, [10]). Studies indicate that extracurricular practices in the schools are done with physical disabilities and limited materials, they do not go beyond the known sports branches (volleyball, basketball, soccer...etc.) and that limited number of students are involved in school team work (Kanters, [10], Pehlivan, [16]). In this research, it is important that archery area related to the Federation is near the school, so that it is possible to introduce the arrow shooting activity, which is a different sports branch to the students as out-of-course activities. In the view of this information, the purpose of this research is to investigate investigation of participation motivations in exercises of students participating in archery in extracurricular activities. For this aim, answers to the following questions were sought.

- Are the motivations for participations in the exercise changing after the students' shooting arrow activity?

- Is the archery skill level of the students changing?

- Are the perspectives of the students towards the course of physical education changing with this activity?

- Have the students' interest in archery increased?

\section{Method}

Research is a mixed-patterned study in which both qualitative, quantitative views and practise were used together.

\subsection{Research Group}

While the study's universe consists of all $11^{\text {th }}$ graders studying at Hazım Kulak Anatolian High school, the sample includes 32 of the $11^{\text {th }}$ grade students who participated in arrow shooting activity in extracurricular activities. These students have not participated in arrow shooting activities before, and do not know how to shoot arrows. In the qualitative part of the study, a total of 18 students including 9 female and 9 male volunteers participated.

\subsection{Procedure}

In this study the students participating in arrow shooting activities in extracurricular activities covers a total of 12 weeks, once a week and two lesson hours. Before the activities, the students were informed about the study and voluntary participation was provided. Later on, the trainer with the second degree coach continued to work with the help of a teacher. Exercise Motivation Questionnaire (EMQ) was applied to the students before and after the study. Shooting arrow skill test, which was prepared together with the teacher and the coach and which was applied to the students before and after the study. The shooting arrow skill test was evaluated by grading over 100 points which was applied to the students before and after the study. Semi-structured interview questions (8 questions) were created by compiling studies made on this subject and taking experts' opinions. These questions were applied to the students at the end of shooting arrow exercise.

\subsection{Data Collection Tool}

In this study, the arrow-shooting activity covers a total of 12 weeks, once a week, two lesson hours. The arrow shooting activity was implemented in the archery hall next to the school and for the application. Necessary permissions were obtained from the school director, parents and archery hall managers. In practices related to shooting arrows, 
assistance was obtained from the national coach with the second-level coach document as well as from the physical education teacher.

\subsubsection{Exercise Motivation Questionnaire (EMQ)}

This scale which was developed for the purpose of adopting it to Turkish were accomplished by Gürbüz, Așçı and Çelebi, [17]to determine the main reasons leading individuals to exercise. Expressions in the scale consisting of 66 items and 5 subscales are scored on a 5-point Likert type scale (Rogers \& Morris, [18]). This scale was applied to the students before and after the study.

\subsubsection{Shooting Arrow Skill Test}

In the study, also an shooting arrow skill assessment test, which was prepared together with the teacher and the coach and which was applied to the students before and after the study to determine their archery skill, was evaluated by grading over 100 points. In applications related to archery, in addition to the physical education teacher assistance was obtained from the national coach who has the second-tier coach document.

\subsubsection{Shooting Arrow Practices}

During the first two weeks of the course lasting 12 weeks, students were given theoretical information about archery sport safety precautions, game rules, field-material information, and achievements in our country and our Olympic status in one part of the lesson. During this time, pre-tests were conducted. After that, skill applications were started. In this application, our aim is to introduce the arrow shooting sport and to learn by the rules. Each week thereafter, the following subjects such as; body posture, tire posture, gripping exercises, holding with the arrow, holding arrows at increasing distances and target exercises have been implemented on the teacher and coach companion. Students participating in this activity within the framework of extra-curricular activities of the school are students who have not been taught to shoot arrows before.

Qualitative Study: Semi-structured interview technique was applied as a qualitative data collection method in the study (Yıldırım et. al., [19]). Semi-structured interview questions (8 questions) were created by compiling studies made on this subject and taking experts' opinions. After informing the students, face to face interviews were made in a closed room by getting appointment on the designated days and by using voice recorder. Negotiations take minimum 15 minutes, maximum 30 minutes. Content analysis method of qualitative analysis methods was used for the analysis of the data obtained from the answers given to the questions by the students participating in the study in an understandable manner. The obtained data were firstly converted to prose in computer environment. The data are then coded by the researcher with the expressions in short sentences. In the findings of the study, the expressions related to themes were coded with the initials of the first and last names of the students (ÖA, HUK... etc.). The school administration and the parents were informed about the study before the research and parents' permission was obtained.

\subsection{Interview Questions}

1. Did you like the shooting arrow activity?

2. Would you like to continue this activity later?

3. Would you recommend this activity to your friends and / or the neighbourhood?

4. Did your perspective on the course of physical education change with this activity?

5. Do you want these different types of activities to be included in the practice of physical education and sports activities?

6. Did your concentration increase with this activity?

7. Did your attention increase with this activity?

8. Did your interest in archery sport increase with this activity?

\subsubsection{Validity and Reliability}

Validity: It has been paid attention that the findings are consistent and meaningful within the study. Obtained findings were ensured to be a whole by the observation of the researcher and an expert who is coding.

Reliability: The researcher clearly identified the methods and stages of the research. The statements obtained in the research were read one by one and coded by the researcher and the expert instructor, after which the themes were constituted. The reliability analysis of the qualitative data was calculated by the formula developed by Miles and Huberman [20] and the reliability was found $80 \%$.

$$
\mathrm{P}(\text { reliability percentage })=\frac{\mathrm{Na}(\text { Agreement })}{\mathrm{Na}(\text { Agreement })+\mathrm{Nd}(\text { Divergence })} \times 100
$$


Table 1. Assessment of Shooting Arrow Skill Test

\begin{tabular}{|c|l|c|}
\hline No & \multicolumn{1}{|c|}{ Variables } & Score \\
\hline 1 & Body Posture (Angle at parallel shoulder width at the feet axis, truncate) & 30 \\
\hline 2 & Spring traction and pedestrian push (Hand grip on left arm brace, right arm angle, right hand middle three fingers position) & 20 \\
\hline 3 & $\begin{array}{l}\text { Sighting and crossing (Keeping the beam and bow on the same line, focusing on the target from the left side of the beam when } \\
\text { the cutting is in progress) }\end{array}$ & 20 \\
\hline 4 & Shoulder and shovel muscles work equally & 10 \\
\hline 5 & $\begin{array}{l}\text { Last move (Slip of the hand towards the ear with the shift of the right hand by pulling the end-point from the beam's finger } \\
\text { knuckles) }\end{array}$ & 10 \\
\hline 6 & Release (After releasing the beam, free movement of the hand pressing the bow ) & 10 \\
\hline & TOTAL & 100 \\
\hline
\end{tabular}

Table 2. Distribution of the Views of Students According to Themes, Codes and Subjects

\begin{tabular}{|l|l|l|}
\hline \multicolumn{1}{|c|}{ Sample Excerpt } & \multicolumn{1}{|c|}{ Code } & Theme \\
\hline $\begin{array}{l}\text { 1- A pleasant activity, ideal for both body and mind development. } \\
\text { 2-I enjoyed it, I have self-confidence. } \\
\text { 3-I liked it, extraordinary. } \\
\text { 4- It surely increased; I used to think it was easy. Now I look at all of them } \\
\text { with respect }\end{array}$ & Activity Acquisitions & Enjoying Activity and Interest \\
\hline $\begin{array}{l}\text { 1-I want to do this sport at university. } \\
\text { 2-I would like to continue it as hobby. } \\
\text { 3-If conditions are possible, I want to continue it. }\end{array}$ & Opinions regarding the activity & Continuing the Activity \\
\hline $\begin{array}{l}\text { 1-Previously, physical education classes were leisure classes, we used to } \\
\text { play football, this activity is very different, and lessons became more } \\
\text { attractive. } \\
\text { 2-Everybody loves physical education courses, Previously girls used to play } \\
\text { volleyball, boys used to play football. Now it has changed. } \\
\text { 3-I did not like physical education courses beforehand, now I look forward } \\
\text { to it. }\end{array}$ & Views on physical education course & Perspectives on Physical \\
\hline $\begin{array}{l}\text { 1-I think my concentration will increase because I am always focusing, I am } \\
\text { slowly gathering up my mind. } \\
\text { 2-I had many calculation errors beforehand, now they decreased. } \\
\text { 3-We keep concentrating there, after a while you start not to hear voices. } \\
\text { 4-It is so useful for the other courses; I am now good at paying attention and } \\
\text { concentrating. }\end{array}$ & Attention and Concentration & Attention and Concentration \\
\hline
\end{tabular}

\section{The Analysis of the Data}

In the research descriptive statistics are used in the quantitative analysis of data, these results are interpreted with frequencies and the averages; in addition, t-test is applied to compare the pre-test and post-test values of the students with their 12-week arrow-shooting skill. The content analysis method was used in the evaluation of the interview questions for the qualitative study, the interviews were first coded separately by the researchers and four themes were constituted by classifying under certain themes (e.g.: Table-2).

\subsection{Themes}

1. Enjoying Activity and Interest

2. Continuing the Activity

3. Views on Physical Education Course

4. Attention and Concentration (Table 2).

Coding of the Data: After reading interview texts line-by-line, the codes that were important to the researcher were highlighted.

Finding Themes: When the codification process was over, the codes were combined by associating with each other in order to form appropriate themes. Thematic coding is to categorize pre-determined codes by designating common aspects (Yıldırım, et. al. [19]).

\section{Findings}

Of the 32 students who participated in the survey, 15 are female, and 17 are male students

Table 3. Numerical Distribution of Research Group

\begin{tabular}{|c|c|c|c|}
\hline & Female & Male & Total \\
\hline $\mathrm{N}$ & 15 & 17 & 32 \\
\hline
\end{tabular}

It was determined that the average scores of students about arrow shooting skill are $(\bar{X}=5,55)$ before the 12 weeks of activity. It was determined that the average scores of students $(\bar{X}=78,94)$ increased after the 12 weeks of activity. A t-test analysis was performed on the related samples to determine whether the increase was significant or not. The results of the analysis showed that this difference was statistically significant $(\mathrm{P}=0.00)$. 
Table 4. The Research Group's Archery Skill Assessment Pre-test and Post-test Results

\begin{tabular}{|c|c|c|c|c|c|c|c|c|}
\hline \multirow{2}{*}{ Arrow-shooting Skill } & \multicolumn{3}{|c|}{ Pre-Test } & \multicolumn{3}{|c|}{ Post-Test } & \multirow{2}{*}{$\mathrm{T}$} & \multirow{2}{*}{$P$} \\
\hline & $\mathrm{N}$ & $\bar{X}$ & Ss & $\mathrm{N}$ & $\bar{X}$ & Ss & & \\
\hline & 32 & 5.55 & 5.23 & 32 & 78.94 & 14.72 & -34.60 & 0.000 \\
\hline
\end{tabular}

Table 5. Pre-test and Post-test T-test Results of Exercise Motivation Questionnaire

\begin{tabular}{|c|c|c|c|c|c|c|c|c|}
\hline \multirow{2}{*}{ Factors } & \multicolumn{3}{|c|}{ Pre-Test } & \multicolumn{3}{|c|}{ Post-Test } & \multirow{2}{*}{$\mathrm{T}$} & \multirow{2}{*}{$\mathrm{P}$} \\
\hline & $\mathrm{N}$ & $\bar{X}$ & Ss & $\mathrm{N}$ & $\bar{X}$ & Ss & & \\
\hline Health & 32 & 3.59 & 0.57 & 32 & 4.60 & 0.34 & 10.77 & 0.000 \\
\hline Competition & 32 & 3.44 & 0.60 & 32 & 3.93 & 0.83 & 2.79 & 0.009 \\
\hline Appearance & 32 & 3.65 & 0.75 & 32 & 4.34 & 0.67 & 4.23 & 0.000 \\
\hline Social and Entertainment & 32 & 3.61 & 0.62 & 32 & 4.53 & 0.48 & 8.49 & 0.000 \\
\hline Skill Development & 32 & 3.95 & 0.74 & 32 & 4.56 & 0.51 & 4.74 & 0.000 \\
\hline
\end{tabular}

When Table 5 was examined, it was determined that the most important motivational factor was "Skill Development" in all students before 12 weeks of activity $(\bar{X}=3,95)$ and afterwards $(\bar{X}=4,56)$. Students' average scores related to subscales in EMQ were found to be "Health $(\bar{X}=3,59)$ ", "Competition $(\overline{\mathrm{X}}=3,44)$ ", “Appearance $(\overline{\mathrm{X}}=3,65)$ ", "Social and Entertainment $(\bar{X}=3,61)$ ", and "Skill Development $(\bar{X}=3$, 95). After 12 weeks of activity, students' average scores were found that "Health $(\bar{X}=4$, 60)", "Competition $(\bar{X}=3,93)$ ", “Appearance $(\bar{X}=4,34)$ ", "Social and Entertainment $(\bar{X}=4,53)$ ", and "Skill Development ( $\bar{X}=4,56)$ " increased in the subscales. A t-test analysis was conducted for the relevant samples to determine whether this increase was significant or not. The results of the analysis showed that this difference was statistically significant.

\subsection{According to the Qualitative Findings of This Study}

\section{Theme 1. Enjoying the Activity and Interest}

While girls indicated that they were very pleased with this activity, male students stated that it was a nice branch to shoot arrows, it increased their self-esteem and that it was an extraordinary activity. They also stated that their attention and concentration on this sport increased, they are now watching things related to archery on the television or on the internet, and that they were unable to do this sport because of inadequate opportunities and they are now pleased that they learned.

"Yes, I enjoyed, I learned how to shoot arrows thanks to you. I learned that archery was a pleasing branch" (EA).

"I liked, I am more self-confident" (HAK).

"I liked, an extraordinary sport" (BH)
"It surely increased; I am even searching on the internet" (FK)

"It increased; I am watching archery series from now on" (KLÜ).

"I was aspiring it on films I watched, I am very pleased that this sport was played in our school" (FA)

"It was the first time that I shot arrows. I was thinking it was going to be easy. It is so hard to do. Now, I have different interest" (ÖFÇ).

\section{Theme 2. Continuing the Activity}

Students stated that they would like to continue their arrow shooting activities if they have opportunities.

"Yes, it was very beneficial for my shoulder development" (MA)

"If I can do it now, I surely want to" (EE)

"I would love to, even; I want to go to the centre of youth"(ED)

"I want to, I am thinking about doing horse archery at university" (ÖFÇ)

"I want to continue. It was my childhood dream" (MAA)

"I want to; I want to shoot arrows in my leisure time" (EA)

\section{Theme 3. Perspectives of Physical Education Course}

Students indicated that their views about the course changed with this activity, the lesson was more fun and that such activities should be included in the physical education program.

"It changed; previously, I did not like physical education lessons. Now, I am looking forward to it. I want it to be included in the program" (EE)

"I would love to; even, it should be compulsory" (EGC)

"We are now more interested in physical education 
courses. I want to, both fun and didactic" (FK)

"Previously, physical education classes were to blow off steam. We used to play football more. This activity is different. This makes the lessons attractive, I wish to take part in the program" (EA)

"Everybody likes the physical education lesson, boys like football and girls like volleyball. Archery activity has changed it. I want it to take place in the program" (KLÜ)

"Physical education class which seems like idle class became worthy of the name, I want it to take part in the program" (HAK)

\section{Theme 4. Attention and Concentration}

Students indicated that their attention and concentration in the lessons increase, and that they focus more quickly, it is beneficial for other lessons and they stated that they will increase more if they participate in the activity more.

"It is beneficial for other lessons. It helped me to gather my attention" (MÇ)

"Yes, it is very good for me to concentrate. I can gather my attention quickly" (HÖ)

"I can gather my attention more quickly, my concentration on the lessons increased" (HS)

"I think it will increase in the future, because I am constantly focusing on the goal and slowly learning to accumulate my mind" (EA)

"Gathering the mind when I aimed made me to gather my attention easier" (KLÜ)

"It increased; especially it was easier to focus on the lessons after I attended the physical education class" (HAK)

\section{Discussion}

Extracurricular activities are the activities for the child; to develop skills and habits related to social values, to develop habits of working an area in which they are interested, to acquire the sense of responsibility, to develop the sense of election, control awareness, righteousness and homework, to help them develop body and soul health, to develop a sense of accomplishment and their existing interests and skills, to acquire a tendency to a profession, to know themselves better, and to develop a self-confidence (Pehlivan, [16]).

In the research, the arrow shooting activity applied to the $11^{\text {th }}$ grade students in the framework of extracurricular activities continued during 12 weeks. An archery skill test was applied to the students before (pre-test) and after (post-test) the practice, and at the end of the practice, a t-test was conducted to show the difference in students' skills. As a result of this analysis, a statistically significant change was determined. Researches indicated that less well-rounded, but well-organized extracurricular activities enhance students' participation and communication with their environment, and they learn increasingly complex skills (Posner, et al. [21], Mohahey, [22]).

In the research, Exercise Participation Motivation Questionnaire was applied to the students before and after the study, and all the participants stated that the most important motivational factor leading to exercise participation is the "Skill Development" before 12 weeks of activity $(\bar{X}=3,95)$ and after that $(\bar{X}=4,09)$. When Kiper's [23] educational institutions were evaluated with male and female students, it was determined that the most important reason for participation in the sport was "Skill Development". Erdoğdu and colleagues, [24] presented girl athletes' most important reason for participation in the sport is the membership of a group, and boy athletes' reason is the Skill Development when they examined the sports participation motivation of the secondary school students who are in school teams in different branches. In the study which Zahariadis and colleagues, [25] evaluated the sports motivation -in physical education lessons- of the primary school students whose average ages are 13, they found that male students were more affected by internal motivational factors (physical appropriateness, skill development and competitions) than the female students.

A statistically significant difference was found after a t-test which was applied in order to determine the difference between the pre-test and post-test averages of the excerpted motivation questionnaire conducted to the students in the study. After 12 weeks of activity, it was determined that students' average scores increased in the sub-dimensions of "Health ", "Competition ", "Appearance", "Social and Entertainment", and "Skill Development. Kanters, [10] stated that with a growing sense of responsibility in children, who have done different sports during school years, a healthy appearance and the development of their skills increase and their spores can become a life style in adulthood.

In terms of enjoyment and interest in the study, the students identified the arrow shooting activity as different from usual practices of the physical education lessons. Turman and Hendels, [26] stated that not only it provides the student participation in new and different recreational activities but also increases participation satisfaction.

In terms of attention and concentration on arrow shooting activity, students indicated that their attention and concentration increased in the lessons, and that it was easier to focus on the lessons. Clifton, [27]pointed out that concentration and focus of students who participated in arrow shooting activity increased on private activities in school and on other lessons in terms of open-air adventure activity for pupils.

\section{Conclusions}

In conclusion, this study emphasized that each child participates in the sport and continues it by being influenced by different motives. Another important issue is that 
motivations vary according to age, gender, type of sport, and experience level. Knowing motives has a great importance for coaches, physical education teachers and families. Coaches, physical education teachers and parents can provide and maintain children's participation in the activity thanks to these motivations. Regarding the positive effects of the sport on children, there is a need to explain and studies on theories about the motivation of spore participation to create a healthy society and to prevent 'immobility', which is the greatest disease of our time.

In terms of attention and concentration on arrow shooting activity, students indicated that their attention and concentration increased in the lessons and their views about the course changed with this activity, the lesson was more fun and that such activities should be included in the physical education program. While girls indicated that they were very pleased with this activity, male students stated that it was a nice branch to shoot arrows, it increased their self-esteem and that it was an extraordinary activity. They also stated that their attention and concentration on this sport increased, they are now watching things related to archery on the television or on the internet, and that they were unable to do this sport because of inadequate opportunities and they are now pleased that they learned.

\section{Recommendations}

1. The arrow shooting activity applied in the context of extracurricular activities in the research increased the interest, participation and desires of the students. For this reason, it is important for physical education teachers to apply different sports (dart, bocce, korfball...etc.) in the physical education and extracurricular activities within the tools and facilities they have, both in terms of increasing the sports culture and increasing the interest and motivation of the students.

2. It is recommended that this type of activity should be applied in the physical education and extracurricular activities lessons, especially in the periods where the examination system is intensive, if we consider that arrow shooting activity applied in the research, it affects students' focusing, increases concentration and their attention according to their opinions.

\section{REFERENCES}

[1] Atabeyoğlu, C. (1988) the History of Archery. Ankara: Turkish Sports Foundation Publications

[2] Randal, G., (1997), "Teaching Archery Games; Tips and Teaching", Camping Magazine, V20n2, and Pp.: 26-29.

[3] Lee, K., (2013).Mental Training for Archers. USA Archery
(Eds). (pp 1-10) Human Kinetics Books.

[4] Kolayiş Eroğlu İ., Mimaroğlu E, (2008) The effects of the heart rate and the time of aiming in the training environment of the Archery National Team on the shooting score, International Journal of Human Sciences

[5] Kürşat Aktepe, (2003), “Archery”, Nobel Publishing Distribution, page; $129-169$

[6] Ekici, S., Bayrakdar, A., Uğur, O. (2009). Investigation of the Views of Secondary School Administrators and Students on Extracurricular Activities. International Journal of Human Sciences, 6: 1, 430- 444.

[7] Ardahan, F., Yerlisu Lapa, T. (2010). Evaluation of the Reasons for the Participation and Nonparticipation of the Students in the Recreation of Activities According to Income and the Coming District: Akdeniz University Example. Celal Bayar University. School of Physical Education and Sports, Physical Education and Sports Science Magazine, 5: 3, 87-96.

[8] Köse, E. (2003). Effects of extracurricular activities at the primary school level on academic achievement and school culture perception, Doctoral Thesis, 25.

[9] Torsheim, T., Sallis, J. F., Samdal, O. (2008). The Characteristics Of The Outdoor School Environment Associated Of Physical Activity. Oxford Journals, Health Education Research, 25: 2, 248- 256.

[10] Kanters, M.A., Michael, B.E., Floyd, F.M., (2013) School Sport Participation under Two School Sport Policies: Comparisons by Race/Ethnicity, Gender and Socioeconomics Status, Ann. Behav. Med., 45 (Suppl.), S113-S121.

[11] Kim, H., Kim, S. and So, Y., (2012)” The Relative Importance of Performance Factors 1 in Korean Archery", 1Department of Sport Psychology, Korea National Sport University, Seoul, Korea, Journal of Strength and Conditioning Research Publish

[12] Soyer, F., Can, Y., Güven, H., Hergüner, H., Bayansalduz, M., Tetik, B. (2010). An Analysis of the Relationship between Success Motivation and Team Alignment in Sports. International Journal of Human Sciences, 7: 1, 225- 238.

[13] Altıntaş, A. (2010). Comparison of Goal Orientations of Athletes, Perceived Motivational Climates and Perceived Physical Competencies According to Sex and Experience Level, M.Sc. Thesis, Ankara University Institute of Health Sciences.

[14] Wann, D. L. (1997). Sport psychology. Upper Saddle River, New Jersey: Prentice-Hall. pp. 158- 183.

[15] Gillard, A., Watts, E.C. and Witt, A.P., (2009), "Camp Supports for Motivation and Interest: Mixed Methods Study", Journal of Park and Recreation Administration, Vol.: 27, No: 2, Pp.: 74-96.

[16] Pehlivan, Z. (2010). Expectations of Families for Children Participating in Sports, Observed Changes in Behaviour in Children and Obstacles in Participation in Sports. Spormetre Journal of Physical Education and Sports Sciences. 7: 2, 6976.

[17] Gürbüz, B., Aşçı, F. H. \& Çelebi, M., (2006), “The Reliability and Validity of the Turkish Version of the "Recreational Exercise Motivation Measure", 9th International Sport Sciences Congress, 1044, 3-5 November, Muğla, Turkey. 
[18] Rogers, H. and Morris, T. (2003). An overview of the development and validation of the recreational exercise motivation measure (REMM), $11^{\text {th }}$ European Congress of Sport Psychology. Congress Proceedings Book, July 22-27, Copenhagen, Denmark.

[19] Yıldırım, A., Şimşek, H., (2013), Qualitative Research Methods in Social Sciences, Expanded Edition 9, Ankara: Seçkin Publishing.

[20] Miles, M.B, and Huberman,A.M.,(1994 ), Qualitative Data Analysis, 2nd Ed., Newbury Park, CA: Sage.

[21] Posner, J. \& Vadell, D., (1999), Development of Low Income Urban Children: A Longitudinal Study, Developmental Psychology, 95(3), 868-879

[22] Mohahey, J. (2000), School Extra Curricular Activity Participation as a Moderator in the Development of Antisocial Patterns, Child Development, 71(2), 502-516

[23] Kiper, H. (2004). Comparison of Motivation of Participation of Students in Sports Institutions According to Gender and Age Groups. Unpublished Master's Thesis. Ege University Health Sciences Institute.

[24] Erdoğdu, M., Şirin, E. F., İnce, A., Öçalan, M. (2010). Examination of Motivation Participation of Secondary School Students in School Teams in Different Branches. 11. International Sports Sciences Congress. Antalya, 633-635.

[25] Zahariadis, P. N., Tsorbatzoudis, H., Grouios, G. (2005). The Sport Motivation Scale for Children: Preliminary Analysis in Physical Education Classes. Perceptual and Motor Skills, 101, 43-54.

[26] Turman, C.J., and Hendel, D.D., (2004) "Changes in Students, Recreation Activities, Satisfaction and Perceived Benefits Following the Construction of New Recreation Facility", Recreational Sports Journal, Vol.: 28, Issue: 2, Pp.: 42-59.

[27] Clifton, L.A., (2014), "Taking Aim, Students Engage in Outdoor Adventure", İndependent School, Vol.: 73, Issue: 3, Special Section, P: 10-10.1p. 